\title{
Effects of high-altitude periodic breathing on sleep and arterial oxyhaemoglobin saturation
}

\author{
A. Salvaggio*, G. Insalaco*, O. Marrone*, S. Romano*, A. Braghiroli+, P. Lanfranchi+, \\ V. Patruno*, C.F. Donner+, G. Bonsignore*
}

Effects of high-altitude periodic breathing on sleep and arterial oxyhaemoglobin saturation. A. Salvaggio, G. Insalaco, O. Marrone, S. Romano, A. Braghiroli, P. Lanfranchi, V. Patruno, C.F. Donner, G. Bonsignore. CERS Journals Ltd 1998.

ABSTRACT: This study aimed to investigate the effect of periodic breathing (PB) at high altitude on sleep structure and arterial oxygen saturation $\left(S_{\mathrm{a}}, \mathrm{O}_{2}\right)$.

Five healthy subjects underwent polysomnographic studies at sea level, and during the first and the fourth week of sojourn at $5,050 \mathrm{~m}$. Their breathing pattern, sleep architecture and $S_{\mathrm{a}, \mathrm{O}_{2}}$ were analysed.

PB was detected in the high-altitude studies during nonrapid eye movement (NREM) sleep and tended to increase from the first to the fourth week. Stages 3-4 were absent in four subjects at the first week, but only in one at the fourth week, irrespective of the amount of $P B$. The arousal index was $11.6 \pm 3.8$ at sea level, $30.1 \pm 15.5$ at the first week at altitude and 33.0 \pm 18.2 at the fourth week. At altitude, arousal index in NREM sleep was higher during PB than during regular breathing. In NREM sleep, the mean highest $S_{a}, O_{2}$ levels in NREM epochs with $P B$ were higher than in those with regular breathing by $2.8 \pm 1.7 \%$ at the first week and $2.9 \pm 1.5 \%$ at the fourth week $(\mathrm{p}<0.025)$. From the first to the fourth week, mean $\mathrm{S}_{\mathrm{a}}, \mathrm{O}_{2}$ increased significantly during wakefulness $(5.6 \%)$, NREM $(5.2 \%$ with regular breathing and $5.3 \%$ with PB) and rapid eye movement sleep $(7.6 \%)$.

The data demonstrate a slight role of periodic breathing in altering sleep architecture at high altitude and also show that periodic breathing induces only a minor improvement in arterial oxygen saturation during nonrapid eye movement sleep. Eur Respir J 1998; 12: 408-413.
*Institute of Respiratory Pathophysiology of the Italian National Research Council, Palermo, Italy. ${ }^{+}$Salvatore Maugeri Foundation, IRCCS, Divisions of Pulmonary Disease and Cardiology, Medical Center of Rehabilitation, Veruno, Italy. of Pneumology, Medical Center of Rehabilitation, Montescano, Italy.

Correspondence: G. Insalaco

Istituto di Fisiopatologia Respiratoria CNR Via Trabucco 180

90146 Palermo

Italy

Fax: 39916882165

Keywords: High altitude

hypoxia

periodic breathing

sleep

Received: April 81997

Accepted after revision March 131998

Supported by the Italian National Research Council, Strategic Project Ev-K²-CNR/92 and by Research Protocol No. 464 (199293) from the Clinica del Lavoro Foundation.
High-altitude environments are characterized by a low barometric pressure. Normal subjects ascending to high altitude experience dyspnoea and tachycardia after moderate efforts and complain of a poor quality of sleep, which may also be demonstrated by electroencephalographic (EEG) recordings $[1,2]$. Soon after ascent, physiological changes occur which counteract the negative effects resulting from the decreased oxygen availability and limit the decrease in arterial oxygen content. These changes include increased ventilatory responsiveness to chemical stimuli, hyperventilation and increased plasma bicarbonate urinary excretion [3-6]. As a result, arterial hypoxaemia is attenuated, but hypocapnia typically appears. Hypocapnic hypoxia seems to be the main determinant of the appearance of periodic breathing (PB) during sleep in the subjects acutely exposed to high altitude [7].

The alterations in sleep quality and sleep breathing pattern have been described in normal subjects at high altitude up until a one-month stay [1, 2, 8-10]. In two papers $[1,2]$ the changes in sleep structure and sleep breathing pattern during a one-month stay at an altitude of 4,800 m and $4,300 \mathrm{~m}$, respectively, have been reported; in both, some trend towards an increase in stages 3-4 nonrapid eye movement (NREM) sleep and a decrease in PB have been reported, but the changes in sleep architecture and in breathing pattern were not correlated. PB could contribute to the poor quality of sleep at high altitude and it is often associated with arousals occurring during the hyperventilatory phase of its cycles $[2,11,12]$. Arousals also occurred during the hyperpnoeic phase of Cheyne-Stokes breathing in patients with congestive heart failure [13]. In these patients, the duration of Cheyne-Stokes respiration has been found to be significantly correlated with a poor sleep structure and a short sleep time [14]. This study sought to ascertain whether a similar correlation could exist in normal subjects at high altitude.

While probably disturbing sleep, PB could be of some advantage to gas exchanges during sleep at high altitude. In this condition, owing to the highly hypoxic environment, arterial oxygen saturation $\left(\mathrm{Sa}_{\mathrm{a}} \mathrm{O}_{2}\right)$ is low and decreases further during sleep $[8,10,11,15]$. Therefore, adaptation mechanisms are required to improve it. It has been proposed that $\mathrm{PB}$, despite determining large swings in $\mathrm{Sa}_{\mathrm{a}} \mathrm{O}_{2}$, could sustain $\mathrm{Sa}_{\mathrm{a}} \mathrm{O}_{2}$ at an average level higher than that resulting from stable breathing [15]; however, this hypothesis has not been demonstrated.

The purposes of this study were to investigate whether $\mathrm{PB}$ is correlated with alterations in sleep structure at high altitude and whether it determines an increase in arterial oxygenation during sleep. 


\section{Methods}

Polysomnographic studies were performed in five healthy Caucasian adults (three males and two females) aged 28-34 yrs (height $171.2 \pm 11.3 \mathrm{~cm}$, weight $65.6 \pm 18.0$ $\mathrm{kg}(\mathrm{mean} \pm \mathrm{sD}))$. They had no known medical problems and were instructed not to ingest alcohol or caffeine on the dates of the studies. They were given no specific training and had been instructed not to go above 2,000 m during the 6 months preceding the expedition. All subjects gave informed consent and the protocol was approved by the local scientific committee on human research.

A baseline polysomnographic study at sea level 1 month before an expedition to the Himalayas was performed in all subjects. This was preceded by an adaptation polysomnography to make the subjects confident with the instrumentation.

Five days after arrival at Kathmandu (Nepal), a Himalayan village at $2,800 \mathrm{~m}$ (Lukla) was reached by aeroplane. Trekking started $2 \mathrm{~h}$ after landing; it never exceeded 5 $\mathrm{h} \cdot$ day $^{-1}$ and included a rest day at $3,400 \mathrm{~m}$. The village of Lobuche, at the altitude of $5,050 \mathrm{~m}(410 \mathrm{mmHg})$, was reached after 6 days of trekking. Sojourn at this altitude lasted for 4 weeks. No subject climbed to a higher altitude during this period. The studies were performed in the Pyramid, a heated and well-equipped laboratory. No one exhibited any symptom of acute mountain sickness, except for subject number 4 who showed oedema of the face and extremities, which disappeared spontaneously within a few days. No polyglobulia was detected in any subject. No subject used medications known to modify ventilatory control (e.g. acetazolamide).

Polysomnographic studies were performed during the first and fourth week of sojourn. The following parameters were continuously monitored: C3A2, C4A1, O1A2 and $\mathrm{O} 2 \mathrm{~A} 1$ electroencephalograms, right and left electrooculograms and chin electromyogram, using an Oxford tape recorder (Medilog 9000, Oxford Instruments, Largo, FL, USA), $\mathrm{Sa}_{\mathrm{a}} \mathrm{O}_{2}$ by pulse oximetry (Ohmeda Biox 3740, Louisville, CO, USA), inspired and expired airflow by nasal prongs connected with a pressure transducer (Hewlett-Pac-kard (HP) 47304A, Palo Alto, CA, USA) and abdomen and ribcage movements by inductive plethysmography (Respitrace Corp., Ardsley, NY, USA). The signals were recorded on an eight-channel (HP3968A) and a four-channel (HP3964A) magnetic tape recorder. Airflow was re-corded on both tape recorders to synchronize all signals. The signals were transferred onto paper after descent to sea level.

Sleep was staged according to standard rules [16]. Arousals were scored visually according to the indications of the American Sleep Disorders Association (ASDA) [17] but the minimum duration required to identify arousals was considered as $1 \mathrm{~s}$. Arousal index was computed as the number of arousals $\cdot \mathrm{h}^{-1}$ of sleep time.

Ribcage, abdomen and airflow signals were visually analysed to distinguish epochs with and without PB. Since airflow was detected only through the nose, PB was defined as a cyclic increase in the amplitude of thoracoabdominal movements, followed by respiratory pauses or hypopnoeas. Hypopnoeas were considered as reductions in the thoracoabdominal movements to at least $50 \%$ of the maximum amplitude during the preceding hyperpnoeic phase of the PB cycle.
The $\mathrm{Sa}_{\mathrm{a}} \mathrm{O}_{2}$ signal was digitized at a sampling rate of 100 $\mathrm{Hz}$ and stored in a Digital VAX 8200 (Digital Equipment Corp., Haynard, MA, USA). Then, a computerized analysis of $\mathrm{Sa}_{2} \mathrm{O}_{2}$ was performed. In each epoch of the polysomnographic study, the lowest, the highest and the mean $\mathrm{Sa}_{\mathrm{a}} \mathrm{O}_{2}$ values were measured. Mean values of lowest $\mathrm{Sa}, \mathrm{O}_{2}$, highest $\mathrm{Sa}, \mathrm{O}_{2}$ and mean $\mathrm{Sa}, \mathrm{O}_{2}$ were calculated separately for NREM sleep with PB, NREM sleep with regular breathing and rapid eye movement (REM) sleep.

One-way analysis of variance, followed by pairwise comparisons by Scheffé's test, was applied to assess differences among data obtained at sea level and the first and fourth week at high altitude. A two-tailed Student's paired t-test was applied for comparisons between $\mathrm{Sa}_{\mathrm{a}} \mathrm{O}_{2}$ data obtained during regular breathing versus $\mathrm{PB}$ or at the first versus the fourth week at high altitude. Linear regression analysis was used to correlate $\mathrm{Sa}, \mathrm{O}_{2}$ values during wakefulness and sleep. Significance was defined as $\mathrm{p}<0.05$. Values are reported as means \pm SD.

\section{Results}

In all high-altitude studies, during NREM sleep stages, both regular breathing and PB were observed. During REM sleep, the breathing pattern was nonperiodic and was characterized by a highly variable respiratory rate and amplitude of respiratory movements. Since PB was observed only in NREM sleep, it was normalized for NREM sleep duration and expressed as a percentage of NREM sleep time spent breathing periodically (\%PB). PB was represented to a variable extent among subjects and showed some increase in all of them at the fourth compared with the first week at high altitude (fig. 1). In the PB cycles, the differences in duration between either respiratory pause or ventilatory phase from the first to the fourth week at high-altitude were not significant (respiratory

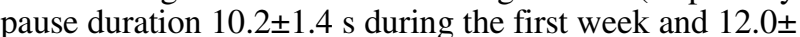
$1.5 \mathrm{~s}$ during the fourth week; ventilatory phase duration $9.3 \pm 1.6 \mathrm{~s}$ and $9.2 \pm 1.2 \mathrm{~s}$, respectively).

Total sleep time (TST) did not differ significantly between sea level $(352.2 \pm 38.5 \mathrm{~min})$, the first week (359.6 $\pm 51.4 \mathrm{~min}$ ) or the fourth week of high-altitude sojourn $(407.8 \pm 31.8 \mathrm{~min})$. Durations of sleep stages, as recorded in each subject at sea level, at the first and the fourth week

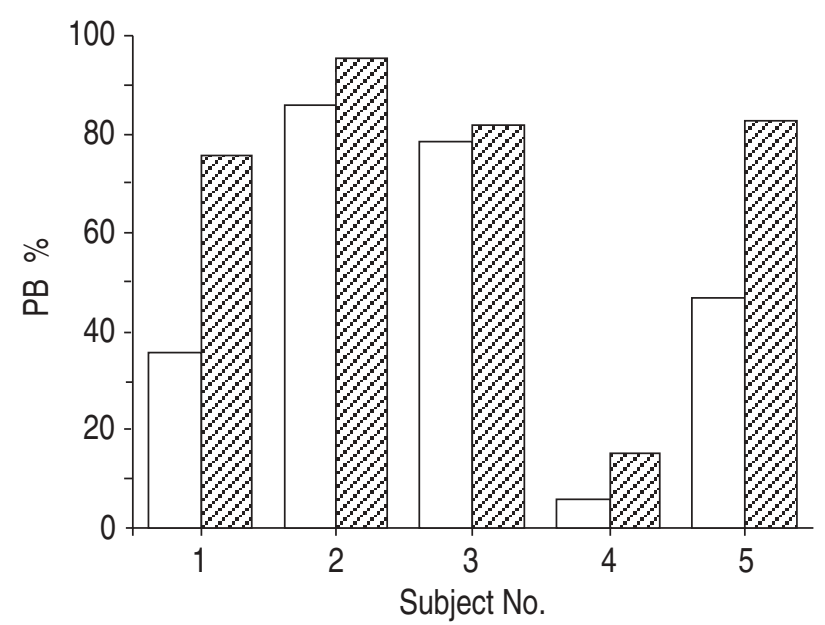

Fig. 1. - Percentage of nonrapid eye movement sleep time spent breathing periodically (PB) during the first ( $\square$ ) and fourth ( $Q 2$ ) week of sojourn at high altitude. 

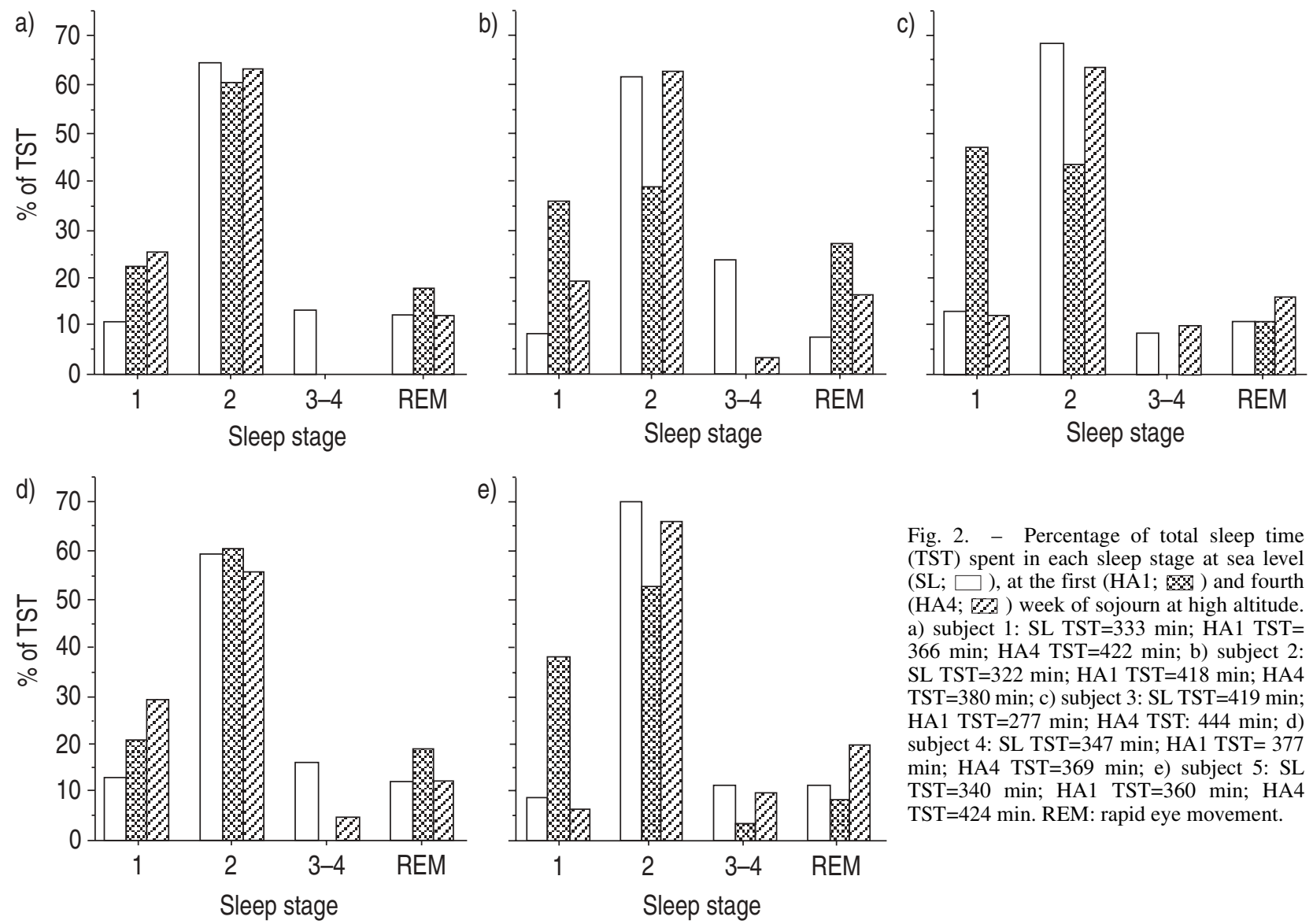

Fig. 2. - Percentage of total sleep time (TST) spent in each sleep stage at sea level (SL; $\square$ ), at the first (HA1; $\infty$ ) and fourth $(\mathrm{HA} 4 ; \mathrm{ZL})$ week of sojourn at high altitude. a) subject 1: $\mathrm{SL}$ TST=333 $\mathrm{min}$; HA1 TST= 366 min; HA4 TST=422 min; b) subject 2: SL TST $=322 \mathrm{~min} ; \mathrm{HA} 1 \mathrm{TST}=418 \mathrm{~min} ; \mathrm{HA} 4$ TST $=380 \mathrm{~min} ; \mathrm{c}$ ) subject $3: \mathrm{SL}$ TST $=419 \mathrm{~min}$; HA1 TST=277 min; HA4 TST: 444 min; d) subject 4: $\mathrm{SL}$ TST $=347$ min; HA1 TST $=377$ min; HA4 TST=369 min; e) subject 5: SL TST $=340 \mathrm{~min} ; \mathrm{HA} 1 \mathrm{TST}=360 \mathrm{~min} ; \mathrm{HA} 4$ TST=424 min. REM: rapid eye movement.

of high-altitude sojourn are reported in figure 2. Stages $3-$ 4 , as percentage of TST, were significantly more represented at sea level than at both the first and fourth week of high-altitude sojourn $(\mathrm{p}<0.05)$. A decrease in stages $3-4$ at high altitude sea level was also observed in the subjects with the smallest amount of PB (subjects 4 and 5), especially at the first week of high-altitude sojourn. Stages 3-4 showed a trend towards an increase from the first to the fourth week of high-altitude sojourn, since they were absent in four subjects in the first-week high-altitude study, while they were missing in the fourth-week study only in one subject.

The arousal index was lower at sea level $(11.6 \pm 3.8)$ than at altitude $(30.1 \pm 15.5$ and $33 \pm 18.2$ at the first and the fourth week, respectively; $\mathrm{p}<0.05$ between sea level and fourth week at altitude). When the analysis was restricted to NREM sleep recorded in the high-altitude studies (table 1), it was higher during $\mathrm{PB}$ than during regular breathing: the difference was significant at the first week at high-altitude $(\mathrm{p}<0.05)$. At the first week of high altitude sojourn, arousals occurred in $25.3 \%$ (range 9.2-45.6) of PB cycles versus $24.6 \%$ (range 12.0-34.9) at the fourth week; these arousals occurred during the hyperventilatory phase of PB cycles.

Values of lowest and highest $\mathrm{Sa}_{\mathrm{a}} \mathrm{O}_{2}$ during regular breathing and PB are shown in figure 3. Both at the first and at the fourth week at high altitude, the lowest $\mathrm{Sa}_{\mathrm{a}} \mathrm{O}_{2}$ in NREM sleep did not differ between $\mathrm{PB}$ and regular breathing; conversely, the highest $\mathrm{Sa}_{\mathrm{a}} \mathrm{O}_{2}$ levels were higher during $\mathrm{PB}$, by $2.8 \pm 1.7 \%$ and $2.9 \pm 1.5 \%$ at the first and fourth week, respectively $(\mathrm{p}<0.025) . \mathrm{Sa}_{2} \mathrm{O}_{2}$ improved at the fourth week in all sleep states and the improvement was independent of the ventilatory pattern (fig. 4). From the first to fourth week, the increase in mean $\mathrm{Sa}, \mathrm{O}_{2}$ during wakefulness was as an average of $5.9 \pm 3.7 \%(\mathrm{p}<0.025)$; during NREM sleep with PB it was $5.3 \pm 4 \%(\mathrm{p}<0.05)$; during NREM sleep with regular breathing $5.2 \pm 3.6 \%(\mathrm{p}<0.05)$; and during REM sleep $7.6 \pm 5.1 \% \quad(\mathrm{p}<0.05)$. Mean $\mathrm{Sa}_{\mathrm{a}, \mathrm{O}_{2}}$ in both NREM (with either PB or regular breathing) and REM

Table 1. - Arousal index for each subject at different times

\begin{tabular}{llrcc}
\hline \multirow{2}{*}{ Subject } & & \multicolumn{3}{c}{ Arousal index } \\
\cline { 3 - 5 } 1 & Time & TST & NREM RB & NREM PB \\
\hline \multirow{4}{*}{2} & SL & 9.2 & & \\
& HA1 & 25.8 & 15.6 & 51.1 \\
& HA4 & 19.2 & 20.2 & 21.0 \\
3 & SL & 8.6 & & \\
& HA1 & 37.3 & 28.2 & 50.6 \\
& HA4 & 54.9 & 9.8 & 66.9 \\
4 & SL & 15.3 & & \\
& HA1 & 53.2 & 26.5 & 70.3 \\
& HA4 & 50.6 & 16.7 & 69.4 \\
5 & SL & 16.3 & & \\
& HA1 & 20.1 & 18.0 & 98.0 \\
& HA4 & 22.5 & 14.3 & 77.1 \\
& SL & 8.8 & & \\
& HA1 & 14.1 & 12.4 & 17.2 \\
\hline & HA4 & 17.7 & 19.2 & 19.3 \\
\hline
\end{tabular}

For each subject, arousal index is given at sea level (SL) in the total sleep time (TST) and at the first (HA1) and the fourth (HA4) week of sojourn at $5,050 \mathrm{~m}$, in the TST and in nonrapid eye movement (NREM) sleep separately for epochs with regular breathing $(\mathrm{RB})$ and with periodic breathing $(\mathrm{PB})$. 

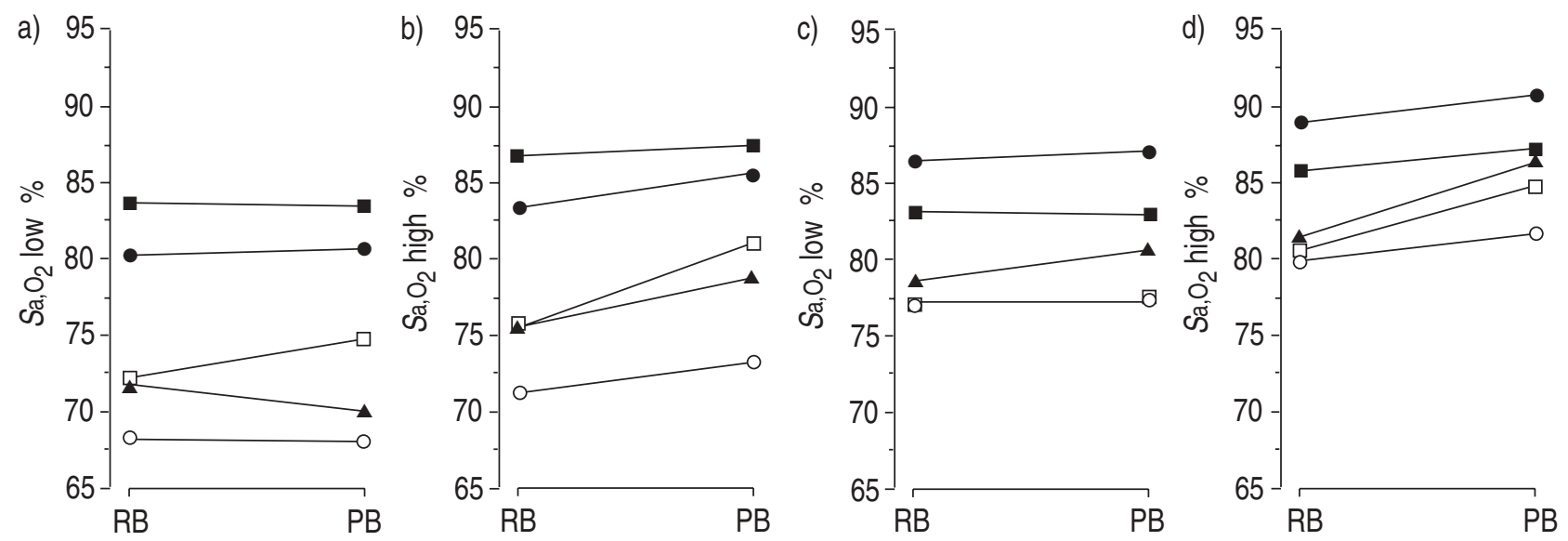

Fig. 3. - Values of lowest arterial oxygen saturation $\left(S_{\mathrm{a}, \mathrm{O}_{2}}\right.$ low) and highest $\mathrm{S}_{\mathrm{a}, \mathrm{O}_{2}}\left(\mathrm{~S}_{\mathrm{a}, \mathrm{O}_{2}}\right.$ high) during nonrapid eye movement sleep with regular (RB) and periodic breathing $(\mathrm{PB})$ at the first $(\mathrm{a}, \mathrm{b})$ and at the fourth $(\mathrm{c}, \mathrm{d})$ week of sojourn at high altitude. $\bullet$ : subject 1: $\square$ : subject 2; $\mathbf{\Delta}$ : subject 3; $\mathrm{O}$ : subject $4 ; \mathbf{m : ~ s u b j e c t ~} 5$.
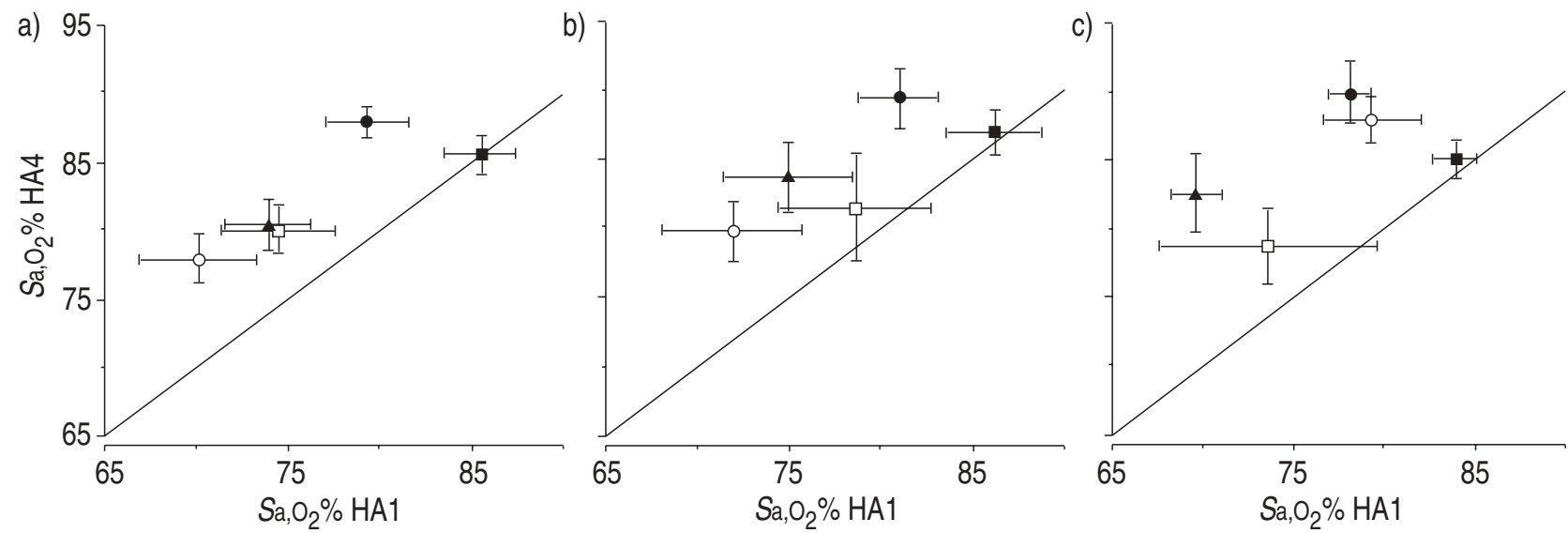

Fig. 4. - Mean arterial oxygen saturation $\left(\mathrm{S}_{\mathrm{a}}, \mathrm{O}_{2}\right)$ during the first (HA1) and fourth (HA4) week of sojourn at high altitude during a) nonrapid eye movement (NREM) sleep with regular breathing, b) NREM sleep with periodic breathing, and c) rapid eye movement sleep for each subject. $\bullet$ : subject 1: $\square$ : subject 2; $\mathbf{\Delta}$ : subject 3; ○: subject 4; $\mathbf{\square}$ : subject 5 .
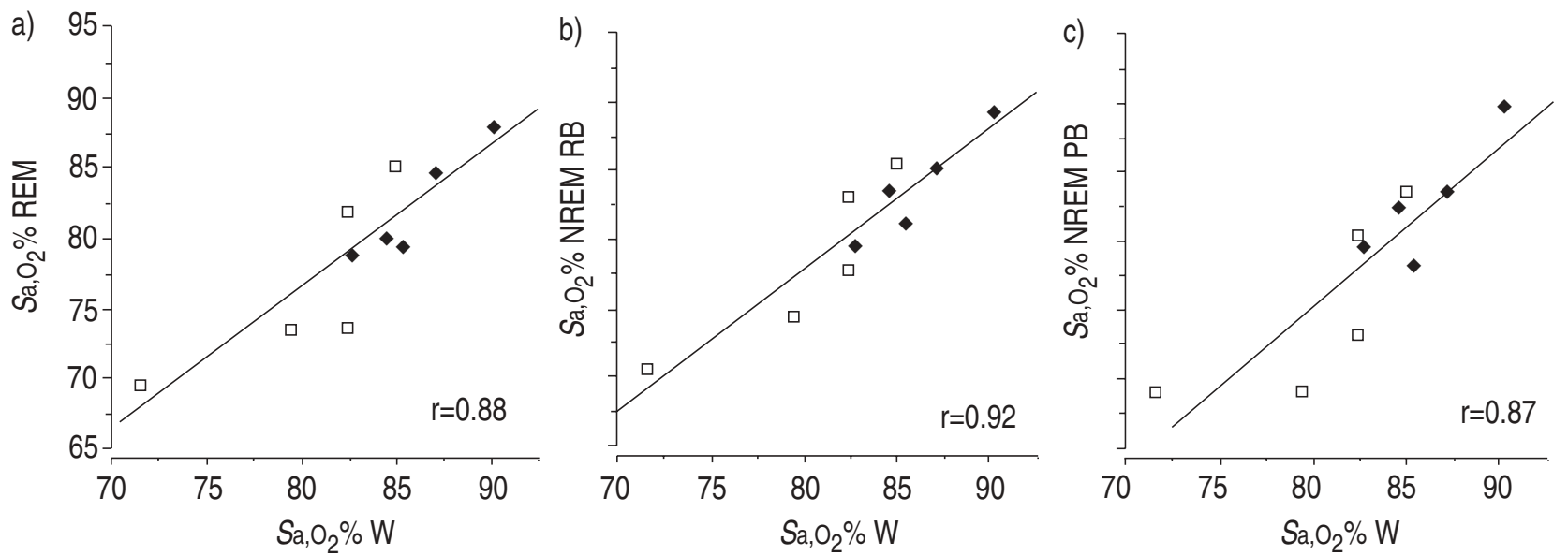

Fig. 5. - Linear correlation of mean arterial oxygen saturation $\left(\mathrm{S}_{\mathrm{a}, \mathrm{O}_{2}}\right)$ in both nonrapid eye movement (NREM), with either periodic breathing (PB) or regular breathing $(\mathrm{RB})$ and rapid eye movement (REM) sleep with $S \mathrm{a}, \mathrm{O}_{2}$ during wakefulness. $\square$ : first week at high altitude (HA1); $\bullet$ : fourth week at high altitude (HA4).

sleep was linearly correlated with $\mathrm{Sa}_{\mathrm{a}} \mathrm{O}_{2}$ during nocturnal wakefulness (fig. 5). As shown in the figure, one subject had a very low $\mathrm{Sa}_{\mathrm{a}} \mathrm{O}_{2}$ during nocturnal wakefulness at the first week at altitude. This subject (number 4) was the only one who experienced oedema of the face and extremities on arrival at high altitude and showed a very low responsiveness to hypoxia, as reported in a previous study [4]. 


\section{Discussion}

This study was aimed at assessing the correlates of PB during sleep at high altitude with $\mathrm{Sa}_{\mathrm{a}} \mathrm{O}_{2}$ and sleep structure, resulting from a three-step evaluation of five subjects ascending to high altitude and staying there for 1 month.

The main findings were: 1) stages 3-4 NREM sleep tended to disappear at high altitude, particularly after acute exposure, even in the subjects who showed small amounts of PB; 2) PB was associated with an increased sleep fragmentation by arousals; 3) PB was associated only with a small increase in $\mathrm{Sa}_{\mathrm{a}} \mathrm{O}_{2}$ with respect to regular breathing; and 4) $\mathrm{Sa}_{\mathrm{a}} \mathrm{O}_{2}$ increased markedly during sojourn at high altitude during both wakefulness and sleep, independently of the breathing pattern.

Although other studies have investigated the effect of sojourn at high altitude on sleep and breathing pattern, this is the first paper in which their simultaneous changes have been evaluated in order to investigate the possible interaction between breathing pattern and sleep structure. In previous papers a trend towards an increase in stages 34 NREM sleep after 4 weeks at altitude was observed, together with some decrease in PB $[1,2]$. PB was also demonstrated until a three to five week stay at high altitude $[1,2,9,10]$. In one of these studies a variable change in $\mathrm{PB}$ duration from arrival at high-altitude to the end of the sojourn was described [2], while in another one a trend towards a decrease was found [1]. Since arousals are often recorded during the hyperventilatory phase of $\mathrm{PB}$ cycles $[1,2,12,14]$, it could have been hypothesized that the stabilization in breathing pattern was associated with a decrease in arousal frequency, which allowed sleep to become more stable and deeper.

The occurrence of arousals was first investigated at sea level, when no PB occurred. EEG arousals are important markers of sleep disruption. Arousals are variably defined in the literature. In many studies they are identified based on the indications given by the ASDA [17]. Other authors prefer to analyse less evident EEG modifications [18-21]. In this study a similar definition was used to those given by MATHuR and Douglas [19] and by ReEs et al. [20], because it allows the visual identification of a high num-ber of sleep disturbances. Compared with the results re-ported by Mathur and Douglas [19], the present subjects showed a lower arousal rate during their sleep at sea level. This difference could be explained considering that these subjects spent an adaptation night in the sleep laboratory before their polysomnography at sea level, while those studied by Mathur and Douglas [19] did not. In any case, the arousal rate found here was in the range described in their study. At high-altitude, the arousal index did not increase significantly with respect to sea level when calculated on the TST; however, as pointed out in previous studies [7, 11, 12], many PB cycles were not associated with arousals, the arousal index was significantly higher during PB than during regular breathing.

This does not allow us to attribute to PB the main responsibility for the lighter sleep structure at altitude than at sea level. The subjects showed a variable amount of PB at altitude, and a clear trend towards an increase in PB from the first to the fourth week. There was a drastic decrease in stages 3-4 NREM sleep with ascent to high-altitude even in those subjects who exhibited a very small amount of PB. With a stay at high-altitude, an increase in stages 3-4 NREM sleep occurred, even though PB did not decrease. These data suggest that the occurrence of $\mathrm{PB}$ is not a major determinant of the poor representation of stages 3-4 NREM sleep at high altitude.

In addition to the arousals detected in this study, more subtle modifications in EEG could have occurred, which could be better demonstrated by computerized analysis and could have shown further sleep disruption induced by the PB. If such modifications actually occurred, that would have not modified the conclusion that the decrease in stages 3-4 at altitude cannot depend entirely on the sleep disruption induced by PB.

The data show that during the first month of exposure to high altitude the process of adaptation to the environment was characterized by a marked increase in $\mathrm{Sa}_{2} \mathrm{O}_{2}$ values during wakefulness and sleep. This improvement occurred in all sleep states and with every breathing pattern. At both the first and fourth week of sojourn at high altitude, $\mathrm{Sa}, \mathrm{O}_{2}$ in every sleep state was correlated with nocturnal $\mathrm{Sa}, \mathrm{O}_{2}$ during wakefulness. Therefore, the mechanisms which lead to an increase in awake $\mathrm{Sa}, \mathrm{O}_{2}$ (particularly the increase in responsiveness to chemical stimuli) [3-5] may also importantly influence $\mathrm{Sa}_{\mathrm{a}} \mathrm{O}_{2}$ values during sleep, irrespective of both sleep state and the occurrence of PB. In the context of the physiological modifications in the ventilatory function appearing at high altitude, PB was associated with a statistically significant increase in the high, but not in the low $\mathrm{S}_{\mathrm{a}} \mathrm{O}_{2}$ values in the NREM epochs. However, the increase was, on average, small, so that its physiological importance was negligible.

In conclusion, periodic breathing during nonrapid eye movement sleep at high altitude is associated with an increase in the arousal rate, thus possibly contributing to the subjective feeling of unrefreshing sleep experienced by subjects sleeping in that environment. However, sleep structure, as represented by the distribution of sleep stages, worsens at altitude irrespective of the amount of periodic breathing. Periodic breathing determines some improvement in arterial oxygen saturation but, in this respect, it is only of minor importance, while other mechanisms are able to sustain arterial oxygen saturation at higher levels in any state of vigilance.

\section{References}

1. Goldenberg F, Richalet JP, Jouhandin M, Gisquet A, Keromes A, Larmignat P. Respiration periodique pendant le sommeil en altitude. Presse Med 1988; 17: 471-474.

2. Reite M, Jackson D, Cahoon RL, Weil JV. Sleep physiology at high altitude. Electroencephalogr Clin Neurophysiol 1975; 38: 463-471.

3. White DP, Gleeson K, Pickett CK, Rannels AM, Cymerman A, Weil JV. Altitude acclimatization: influence on periodic breathing and chemoresponsiveness during sleep. J Appl Physiol 1987; 63: 401-412.

4. Insalaco G, Romano S, Salvaggio A, et al. Cardiovascular and ventilatory response to isocapnic hypoxia at sea level and at 5,050 m. J Appl Physiol 1996; 80: 1724-1730.

5. Sato M, Severinghaus JW, Bickler P. Time course of augmentation and depression of hypoxic ventilatory responses at altitude. J Appl Physiol 1994; 77: 313-316.

6. Crawford RD, Severinghaus JW. CSF $\mathrm{pH}$ and ventilatory acclimatization to altitude. J Appl Physiol 1978; 45: 275283. 
7. Berssenbrugge A, Dempsey J, Iber C, Skatrud J, Wilson P. Mechanisms of hypoxia-induced periodic breathing during sleep in humans. $J$ Physiol 1983; 343: 507-524.

8. Normand $\mathrm{H}$, Barragan $\mathrm{M}$, Benoit $\mathrm{O}$, Bailliart $\mathrm{O}$, Raynaud J. Periodic breathing and $\mathrm{O}_{2}$ saturation in relation to sleep stages at high altitude. Aviat Space Environ Med 1990; 61: 229-235.

9. Lahiri S. Dynamic aspects of regulation of ventilation in man during acclimatization to high altitude. Respir Physiol 1972; 16: 245-258.

10. West JB, Peters RM Jr, Aksnes G, Maret KH, Milledge JS, Schoene RB. Nocturnal periodic breathing at altitudes of 6,300 and 8,050 m. J Appl Physiol 1986; 61: 280-287.

11. Anholm JD, Powles ACP, Downey R III, et al. Operation Everest II: arterial oxygen saturation and sleep at extreme simulated altitude. Am Rev Respir Dis 1992; 145: 817-826.

12. Khoo MCK, Anholm JD, Ko SW, et al. Dynamics of periodic breathing and arousal during sleep at extreme altitude. Respir Physiol 1996; 103: 33-43.

13. Hanly P, Zuberi-Khokhar N. Daytime sleepiness in patients with congestive heart failure and Cheyne-Stokes respiration. Chest 1995; 107: 952-958.

14. Hanly PJ, Millar TW, Steljes DG, Baert R, Frais MA, Kryger MH. Respiration and abnormal sleep in patients with congestive heart failure. Chest 1989; 96: 480-488.
15. Masuyama S, Kochiyama S, Shinozaki T, et al. Periodic breathing at high altitude and ventilatory responses to $\mathrm{O}_{2}$ and $\mathrm{CO}_{2}$. Jpn J Physiol 1989; 39: 523-535.

16. Rechtschaffen A, Kales A. A manual of standardized terminology, techniques and scoring system for sleep stages of human subjects. Los Angeles, CA, BIS/BRI, UCLA, 1968.

17. Atlas Task Force of the American Sleep Disorders Association. EEG arousals: scoring rules and examples. Sleep 1992; 15: 174-184.

18. Chesire K, Engleman H, Deary I, Shapiro C, Douglas NJ. Factors impairing daytime performance in patients with sleep apnea/hypopnea syndrome. Arch Intern Med 1992; 152: 538-541.

19. Mathur R, Douglas NJ. Frequency of EEG arousals from nocturnal sleep in normal subjects. Sleep 1995; 18: 330333.

20. Rees K, Spence DPS, Earis JE, Calverley PMA. Arousal responses from apneic events during non-rapid-eye-movement sleep. Am J Respir Crit Care Med 1995; 152: 1016-1021.

21. Collard P, Dury M, Delguste P, Aubert G, Rodenstein DO. Movement arousals and sleep-related disordered breathing in adults. Am J Respir Crit Care Med 1996; 154: 454-459. 